\title{
URBAN GROWTH AND BEACH NOURISHMENT: EXPERIENCES ON THE COAST OF ALICANTE, SPAIN
}

\author{
JOSÉ IGNACIO PAGÁN, ISABEL LÓPEZ, ANTONIO JOSÉ TENZA-ABRIL, \\ LUIS ARAGONÉS \& YOLANDA VILLACAMPA \\ Department of Civil Engineering, University of Alicante, Spain
}

\begin{abstract}
Since the 1960s, the promotion and development of tourism in coastal towns has turned them into a remarkable source of wealth, linked to a significant population growth in recent decades. This growth has led to a major urban development generating densely populated areas that have had an extraordinary impact on the coasts. The urban growth occupying the dunes, the mass tourism, the continuous construction of marinas and commercial ports, promenades and groynes have led to an increase in the erosion that has affected the shoreline. In this work, the historical evolution of 6 beaches on the coast of Alicante (Spain) has been analysed from aerial images in a period between 1956 and 2017. Both changes in land use associated with the process of urban development and the evolution of the shoreline have also been studied. These beaches are located in population centres whose urban growth has influenced the anthropic actions on the beaches, most of them with relevant problems of erosion. The urban area increased from $30 \%$ to more than $70 \%$ during this period. To avoid coastal damages and to improve the touristic offer, these beaches were nourished in the 1990s, changing the type of sediment that formed them from gravel to sand. In most cases, the filled material has been lost nowadays, returning to the initial stage and even causing environmental damage to the nearby Posidonia oceanica meadows. In order to plan future actions, it is important to be aware of the effects of the past ones carried out. Alternatives should be developed in a sustainable manner with criteria of circular economy, with adequate volumes of fills to maintain their tourist attraction and defence function of the coast.
\end{abstract}

Keywords: Alicante, beach nourishment, urban growth, GIS, shoreline evolution.

\section{INTRODUCTION}

International tourism has grown rapidly over the last 60 years to become one of the world's largest economic sectors, with a significant contribution to many economies, both national and local [1]. The uses and activities carried out in the coastal area are diverse, which has led to numerous anthropogenic actions that have generated imbalances in the area, for example, the construction of ports [2], urbanizations, canalizations or jetties on the coast [3], [4]. These imbalances are generally related to the retreat of the shoreline, which causes the vulnerability of any settlement around it [5].

Coastal and recreational tourism has a prosperous development, which has led to a large urban growth in coastal areas. This has resulted in a significant demographic growth in recent decades, generating a large urban development creating densely populated areas that have had an extraordinary impact on the Levantine coasts. Since the 1960s, the Spanish Mediterranean coastline has been subject to socio-political, economic and environmental changes at local, national and even international levels. These have meant an important change in the appearance of the Spanish east coast, its morphology and consequently the coastal dynamics of the area have also been affected [4].

Among the variety of factors that beach users demand, such as the quality of water, services or access to the beach, is the material that forms it. Its characteristics, such as grain size, colour or morphology can increase the demand for a beach and the satisfaction of its users [6]. In order to increase the tourist attractiveness of its beaches and promote urban development, some municipalities requested a change in the typology of their beaches, 
from gravel to sand, through nourishment projects. The urban developments were executed but the nourishments did not achieve the expected result [4], [7].

The method used to evaluate the impact of erosion on beaches has been the use of aerial photography and classical topography. They were sufficiently valid methods to evaluate those factors that were eminently visible and easily measurable. Currently, the factors that affect beach erosion are more complex, more intense and have a greater impact on the environment. Historically, the tracing of the shoreline has been an arduous task with important methodological and technical limitations, but at present the use of geographic information systems (GIS) has become a great advance in this field. GIS integrate data from several sources (cartography, orthophotography, satellite images) that allow us to obtain and compare the evolution in time of the shoreline [8]. These tools have widely been used in the historical analysis of the shoreline trend changes from aerial images, by means of applications such as Digital Shoreline Mapping System, DSAS [9].

To understand the evolution of land use, satellite images are the main means of differentiating land cover. The CORINE Land Cover (Coordination of Information on the Environment) project, also known by the acronym CLC, develops the creation of a database on land cover and use in the European Union from 1990 to 2012 [10]. Artificial land cover areas can be analysed to identify urban areas and patterns of urbanisation. On the one hand, most of coastal vacant spaces have been occupied, while those already occupied extended inland. On the other hand, the construction of motorways and other roads greatly improved access to new inner areas. Land transformations have significantly changed the character of the territory by creating new opportunity spaces; however, these were not exempt from considerable environmental and economic costs [11].

In this research, a study has been carried out on the evolution of various beaches with the aim of finding out about their changing trends in the past, their current state and future progression and their relationship with the massive urbanisation of the surroundings of these beaches.

\section{AREA OF STUDY}

Our research has studied various beaches located on the Spanish Mediterranean coast, in the province of Alicante, whose main characteristics to date are described in Table 1. All of them are located in highly urbanized environments and were nourished in the 1990s. Their situation can be seen in Fig. 1.

\section{METHODOLOGY}

he methodology followed has consisted, on the one hand, in the study of the evolution of the coastline from aerial images from 1956 to 2017. On the other hand, the land use data

Table 1: Current characteristics of the beaches studied.

\begin{tabular}{|l|l|l|l|l|l|}
\hline BEACH & $\begin{array}{l}\text { Length } \\
(\mathrm{m})\end{array}$ & $\begin{array}{l}\text { Width } \\
(\mathrm{m})\end{array}$ & $\begin{array}{l}\mathrm{D}_{50} \\
(\mathrm{~mm})\end{array}$ & Beach material & Promenade \\
\hline Portet de Moraira & 360 & 20 & 0.311 & Medium greyish sand & Yes \\
\hline Arenal & 1,375 & 45 & 0.260 & Medium greyish sand & Yes \\
\hline Poniente & 3,000 & 80 & 0.283 & Medium golden sand & Yes \\
\hline Centro & 1,220 & 67 & 0.231 & Medium greyish sand & Yes \\
\hline Carrer de Mar & 1,444 & 68 & 0.320 & Medium greyish sand & Yes \\
\hline San Juan & 6,590 & 100 & 0.225 & Fine greyish sand & Yes \\
\hline
\end{tabular}




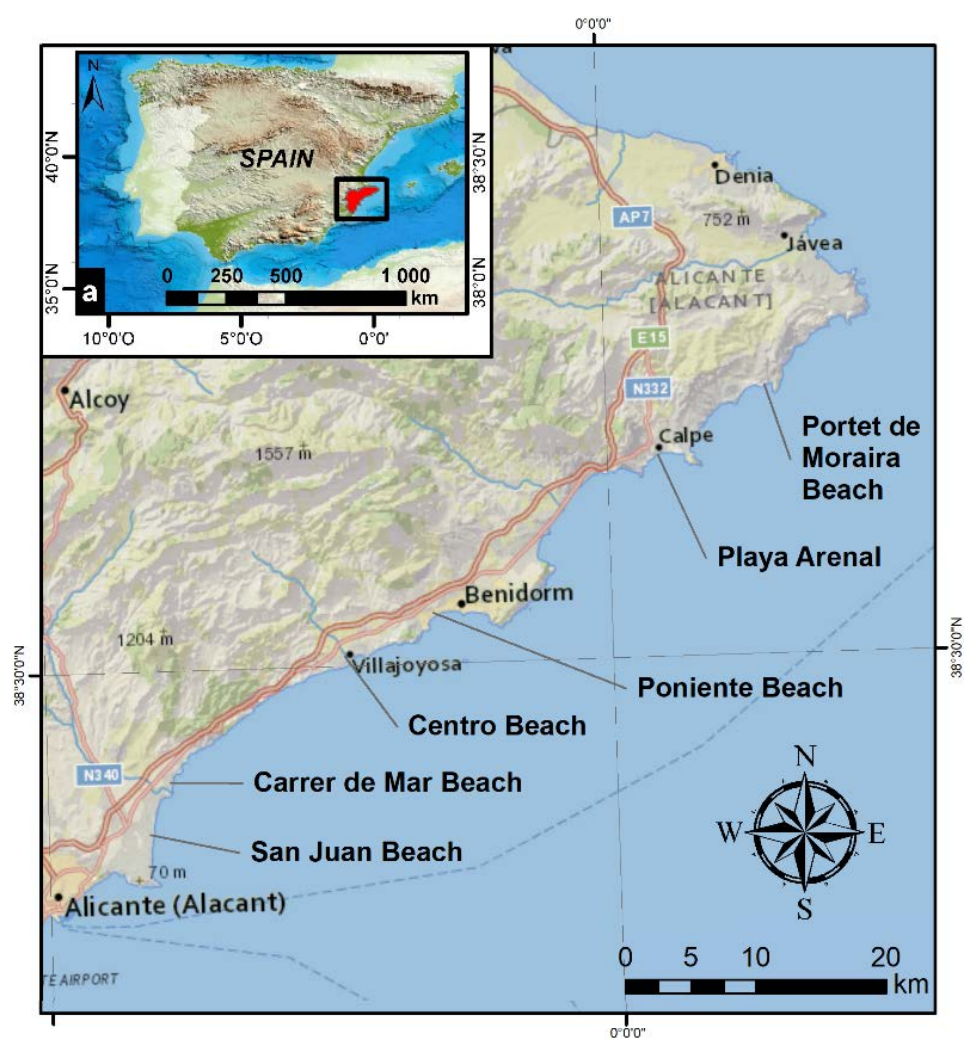

Figure 1: Location of the beaches.

of the CORINE Land Cover programme for the years 1990, 2000, 2006 and 2012 have been used to evaluate the urban growth.

\subsection{Shoreline evolution}

The DSAS program for ArcGIS were used, increasing its capacities with obtaining the erosion-reaction surfaces [4]. In order to measure the evolution of the coast, a series of transects perpendicular to it were created, spatially separated by $100 \mathrm{~m}$. The origin of these transects is at the beginning of the promenades, and they are approximately $200 \mathrm{~m}$ long towards the sea, so that from their intersection with the previously vectorized shorelines the beach width is obtained for each transect in every period of time studied (Fig. 2).

\subsection{Changes in land cover}

The CORINE Land Cover polygons are used to identify the urbanised coastal area within a $2 \mathrm{~km}$ radius of the beaches under study. The collection of land use data is based on a basic terminology that distinguishes between artificial surfaces, agricultural areas, forest and semi-natural areas and wetlands. Artificial areas include urban fabric, industrial, commercial and transport units, dump and construction sites and artificial non-agricultural vegetated areas, such as green urban areas or sport facilities. This classification corresponds 


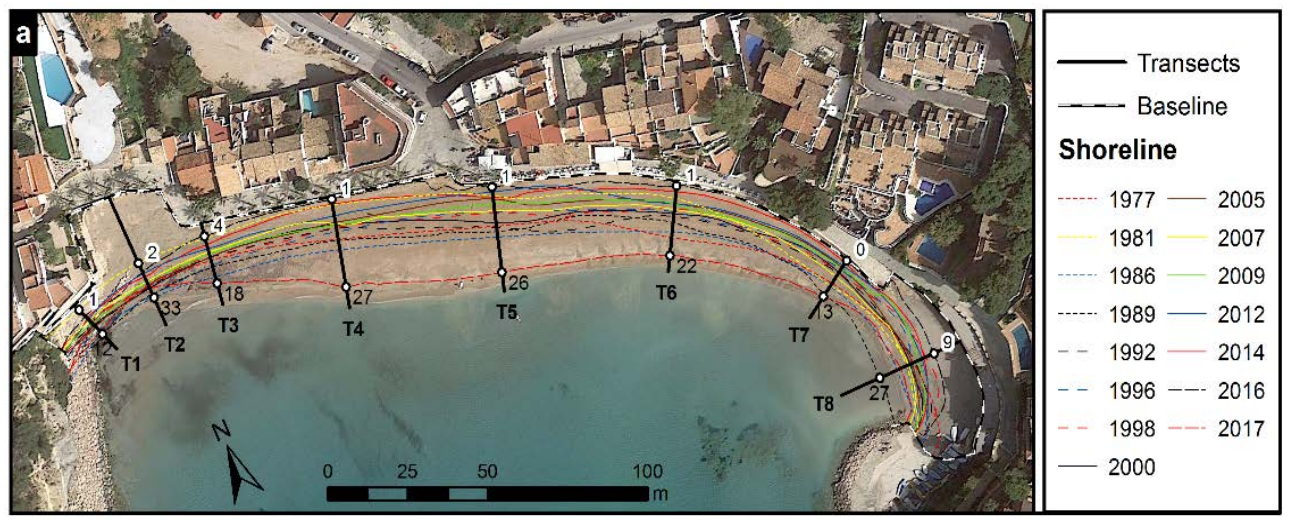

Figure 2: Example of shoreline analysis at Portet de Moraira beach.

Table 2: Average beach width $(\mathrm{m})$ and urban area $(\%)$ in each period.

\begin{tabular}{|l|l|l|l|l|l|l|l|l|}
\hline & \multicolumn{2}{|l|}{1990} & 2000 & \multicolumn{2}{l|}{2006} & \multicolumn{2}{l|}{2012} \\
\cline { 2 - 9 } & $\begin{array}{l}\text { Beach } \\
\text { width }\end{array}$ & $\begin{array}{l}\text { Urban } \\
\text { surface }\end{array}$ & $\begin{array}{l}\text { Beach } \\
\text { width }\end{array}$ & $\begin{array}{l}\text { Urban } \\
\text { surface }\end{array}$ & $\begin{array}{l}\text { Beach } \\
\text { width }\end{array}$ & $\begin{array}{l}\text { Urban } \\
\text { surface }\end{array}$ & $\begin{array}{l}\text { Beach } \\
\text { width }\end{array}$ & $\begin{array}{l}\text { Urban } \\
\text { surface }\end{array}$ \\
\hline PORTET & 14 & $59 \%$ & 12 & $67 \%$ & 5 & $69 \%$ & 3 & $70 \%$ \\
\hline ARENAL & 5 & $58 \%$ & 29 & $67 \&$ & 25 & $70 \%$ & 20 & $70 \%$ \\
\hline PONIENTE & 10 & $36 \%$ & 53 & $53 \%$ & 33 & $60 \%$ & 29 & $63 \%$ \\
\hline CENTRO & 4 & $11 \%$ & 34 & $31 \%$ & 38 & $35 \%$ & 39 & $53 \%$ \\
\hline CARRER & 13 & $29 \%$ & 73 & $38 \%$ & 65 & $41 \%$ & 61 & $60 \%$ \\
\hline SAN JUAN & 7 & $37 \%$ & 74 & $61 \%$ & 81 & $66 \%$ & 87 & $72 \%$ \\
\hline
\end{tabular}

to levels 1 and 2 of CORINE Land Cover. The reference date for the database is the date on which the satellite data used as basic data were acquired (1990, 2000, 2006 and 2012).

\section{RESULTS}

The results of the analysis of the evolution of the shoreline and urban growth are summarized in Table 2. The detailed results for each beach are presented as follows.

\subsection{El Portet de Moraira beach}

The beach has suffered a continuous process of erosion over the years as a result, among other factors, of the lack of contributions due to the urbanization of the basin. In 1985 it was nourished with $26,000 \mathrm{~m}^{3}$ of sand from dredging and in March 2017, with 5,300 $\mathrm{m}^{3}$ from sand quarry. After this last fill, a great turbidity and change of colour of the water was spotted. In the period 1977-1981 a generalised loss of width along the entire length of the beach is detected, with an average value of $-0.79 \mathrm{~m} /$ year. After the 1985 contribution an average increase of $2 \mathrm{~m}$ compared to the 1977 shoreline is detected. However, the width gained from this spill is lost in the next period analysed, with a loss of $9.5 \mathrm{~m}$ of beach width. With the nourishment of 2017 an average increase of $6 \mathrm{~m}$ compared to 1977 and an average width of about $20 \mathrm{~m}$ is achieved. 
The area around El Portet de Moraira beach has had a high degree of urbanization since before the 1990s (Fig. 3). Precisely, 59\% of the surface area of the $2 \mathrm{~km}$ surrounding the beach was classified as artificial surface in 1990, increasing up to $69 \%$ in 2006 . More than 1,000 ha correspond to urban fabric.

\subsection{Arenal beach}

This beach is located in Calpe. In 1992 the beach width was non-existent in a stretch of 500 $\mathrm{m}$ in its central position. The 1993 nourishment meant an increase in the average width of $50 \mathrm{~m}$. However, from then until 2005, erosion rates of $-1.3 \mathrm{~m} /$ year continued to erode the beach. Since a second nourishment in 2002, the beach has shown a stable trend, except in the western part where erosion has been detected next to the groyne.

An increase in the urbanised area is detected (Fig. 4), since where there was previously heterogeneous agricultural lands in the coastal zone it is now an urban fabric, with an increase of almost 100 ha. In each period of time, there are areas under construction, with up to $70 \%$ of the coastline being urbanised in 2012 .

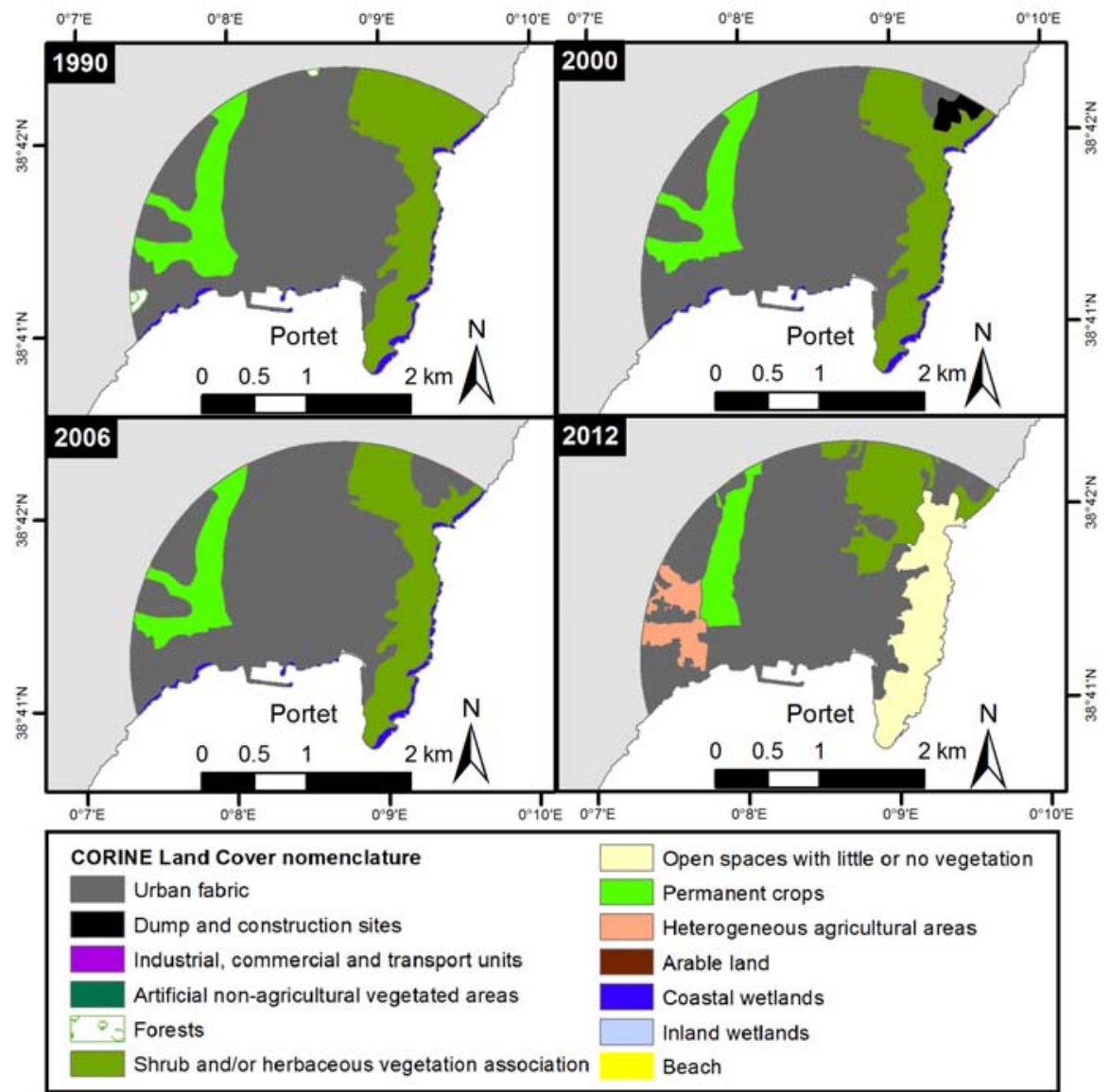

Figure 3: Land cover for El Portet de Moraira beach. 


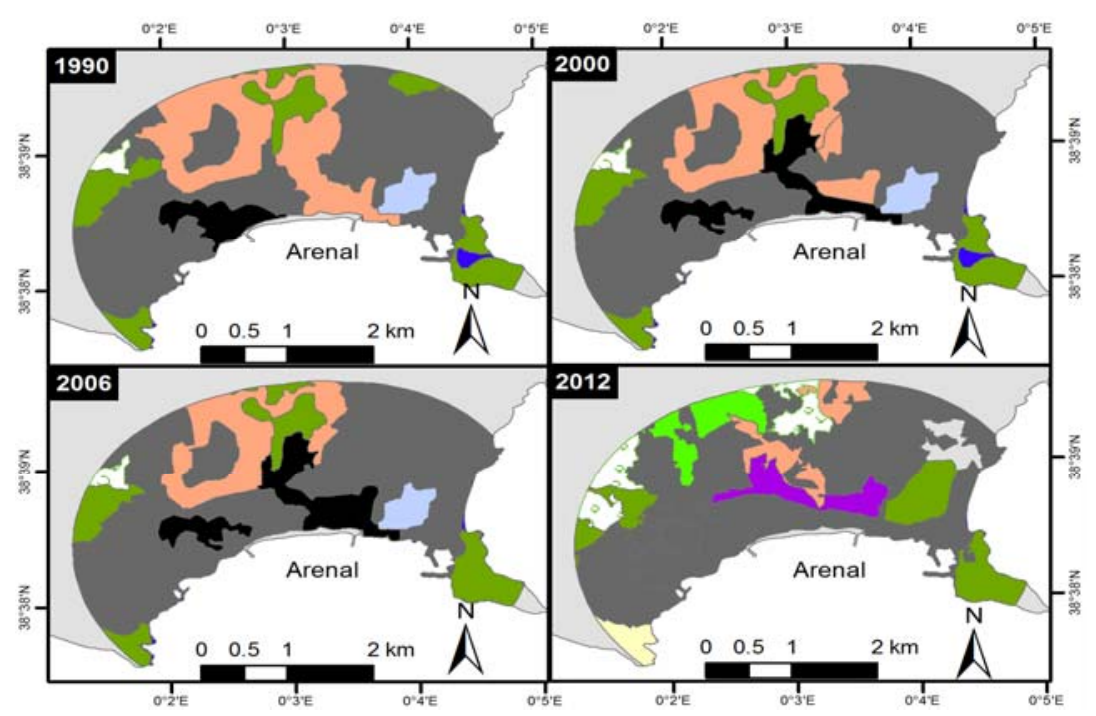

Figure 4: Land cover for Arenal beach.

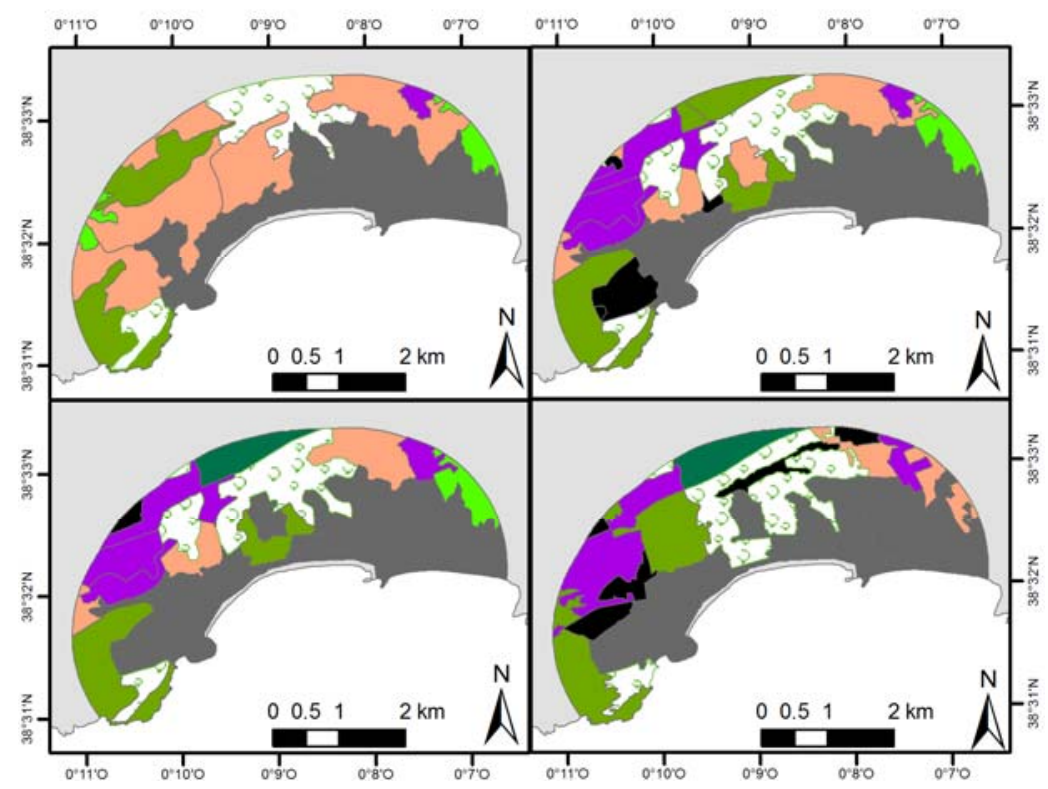

Figure 5: Land cover for Poniente beach.

\subsection{Poniente beach}

This is one of the most famous beaches in Spain, located in Benidorm. This beach has historically suffered a strong urban pressure and in 1991 was nourished with more than 
$710,000 \mathrm{~m}^{3}$ of sand from Serra Helada borrow pit, and a $100 \mathrm{~m}$ semi-submerged groyne was built to support the fillings. When analysing the evolution by periods, until 1990 the beach showed an erosive trend with an average rate of $-0.25 \mathrm{~m} /$ year, a little more pronounced towards the centre of it. In this eastern stretch of the beach is where the greatest loss of material occurs. As its wide was only of $10 \mathrm{~m}$, the waves affected the promenade during the storms. After the nourishment, the beach width increases by an average of $70 \mathrm{~m}$, although later erosion rates reached up to $2 \mathrm{~m} /$ year. The volume of sand dumped buries part of the existing Posidonia oceanica meadow, destabilizing the profile. When the beach profile tried to reach the equilibrium profile, the regression of the shoreline intensified.

The consequence was the loss of the gained width. In terms of urban growth, there is a significant change, from $36 \%$ in 1990 of artificial surface up to $63 \%$ in 2012 (Fig. 5).

\subsection{Centro beach}

This beach is located in Villajoyosa, and it was a gravel beach that was nourished with sands in the early 1990s. The first nourishment involved an increase of beach surface from $10,000 \mathrm{~m}^{2}$ to more than $60,000 \mathrm{~m}^{2}$. However, after this nourishment, $12.8 \%$ of the beach area was lost in the first few years. After a second filling carried out in 2002, the beach seems to be stable with an average width of $40 \mathrm{~m}$. In this case, the urban growth is evident, from $11 \%$ in 1990 to $53 \%$ in 2012 (Fig. 6). This means that the urban fabric increases from 78 ha to more than 415 ha in the same period, an increase of $382 \%$. As usual, it is the agricultural areas that see their extension reduced.

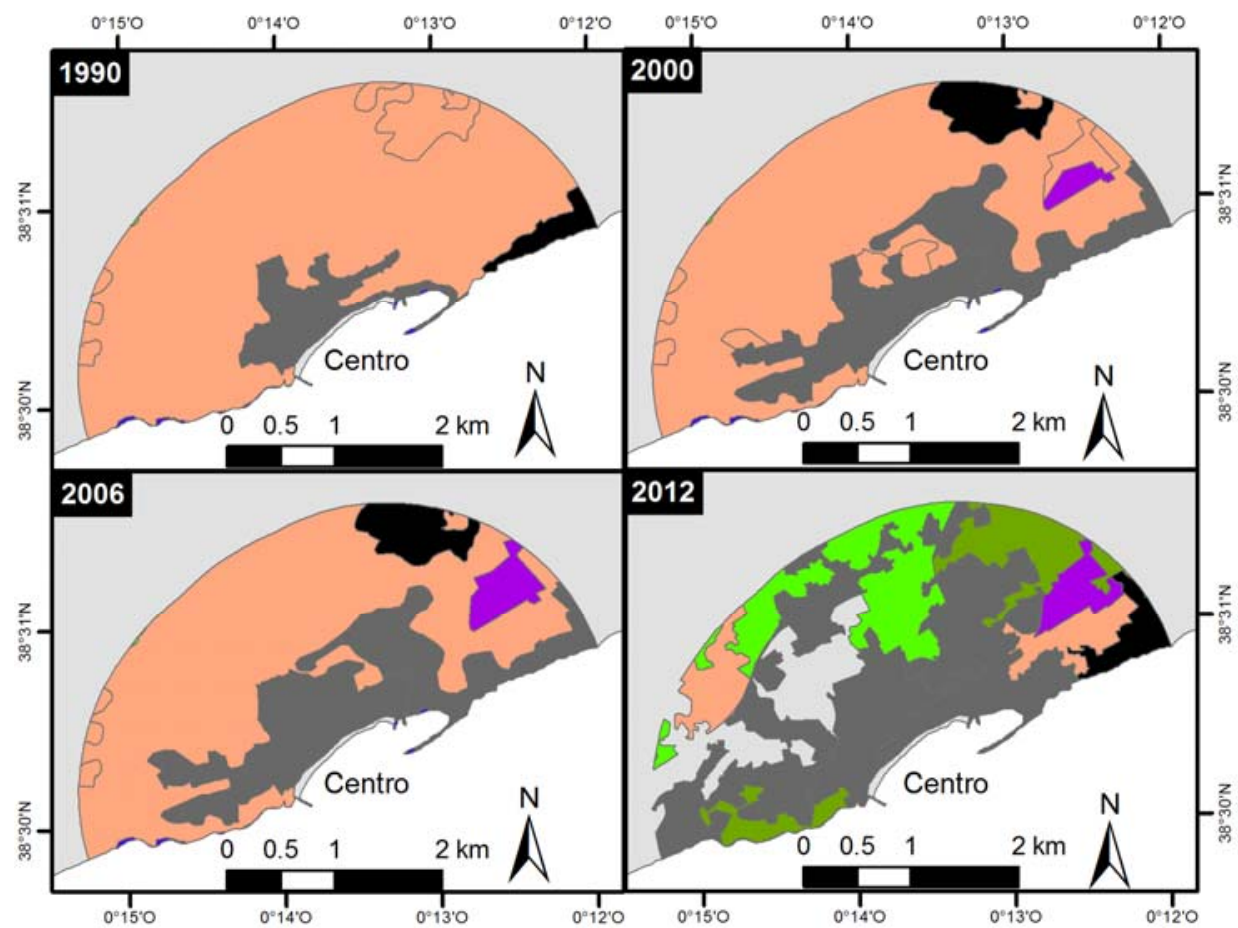

Figure 6: Land cover for Centro beach. 


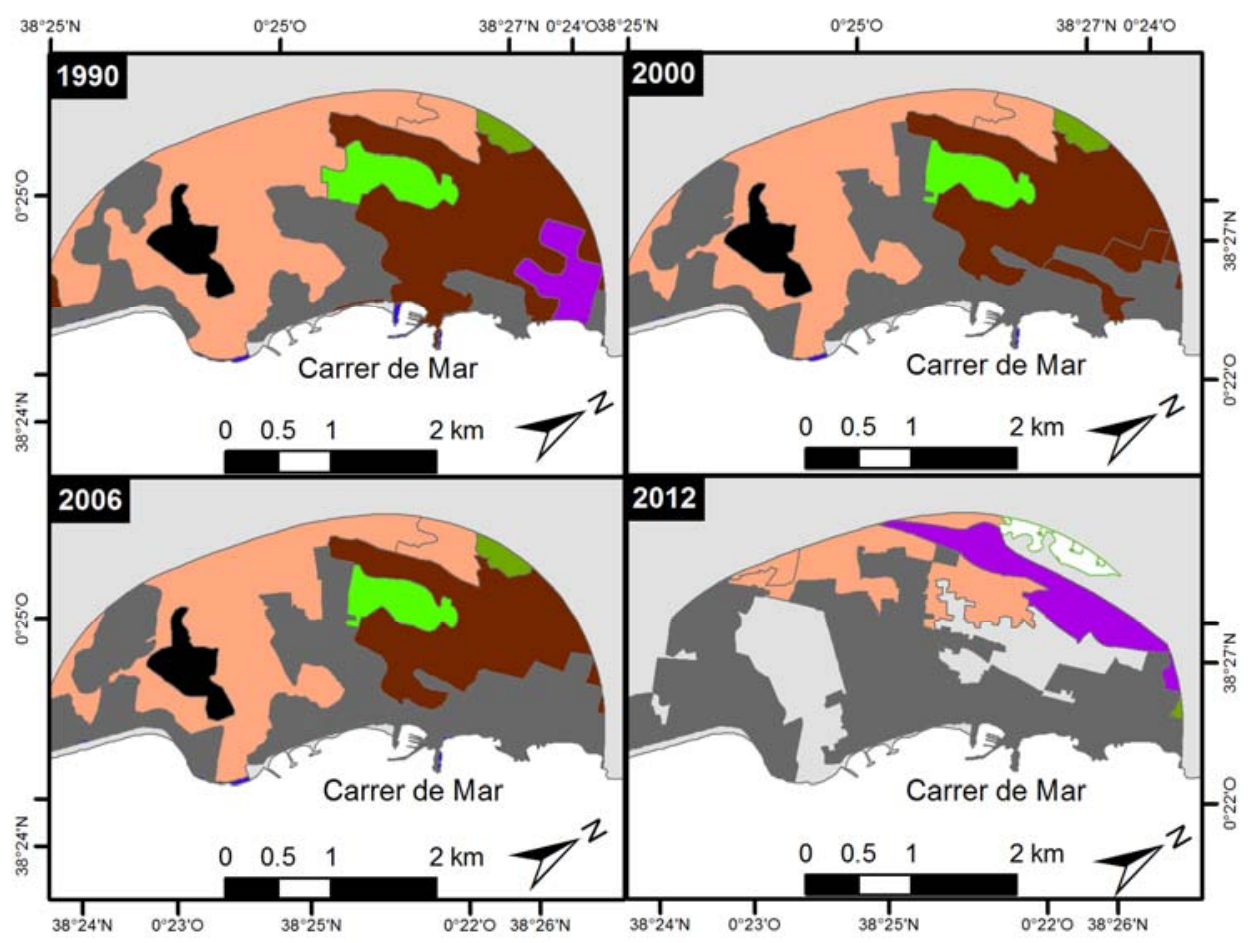

Figure 7: Land cover for Carrer de Mar beach.

\subsection{Carrer de Mar beach}

This beach is located in El Campello, and it was a gravel beach that was nourished with sands in the early 1990s. After the first nourishment, $20.9 \%$ of the beach area was lost in the first years, remaining relatively stable at $50,000 \mathrm{~m}^{2}$ until the second nourishment in 2002, which increased the surface area up to $100,000 \mathrm{~m}^{2}$. After this filling, the erosion trend returns until nowadays, with an average beach width of $61 \mathrm{~m}$.

A progressive urbanization of the beach environment over the years is detected (Fig. 7), passing from $29 \%$ of artificial area in 1990 (270 ha) to 60\% in 2012, with 556 ha occupied by urban fabric. In this case, this urban growth was related to the development of touristic complexes and it was at the expense of the agricultural areas surrounding the town of El Campello.

\subsection{San Juan beach}

This beach is located in two municipalities, Alicante and El Campello. A clear regression of the shoreline is detected between 1956 and 1990, particularly in the southern area closest to Cape Huertas, where a loss of $30 \mathrm{~m}$ of beach is detected. Moreover, its width was zero in some stretches, with the waves hitting the houses causing damages. After the nourishment in early 1990s, the beach width increased by an average of $58 \mathrm{~m}$. Since then, the northern zone shows a stable behaviour, while the southern zone is tilting, with erosion in the most extreme zone of the beach. The 1991 nourishment involved an increase in beach area of 


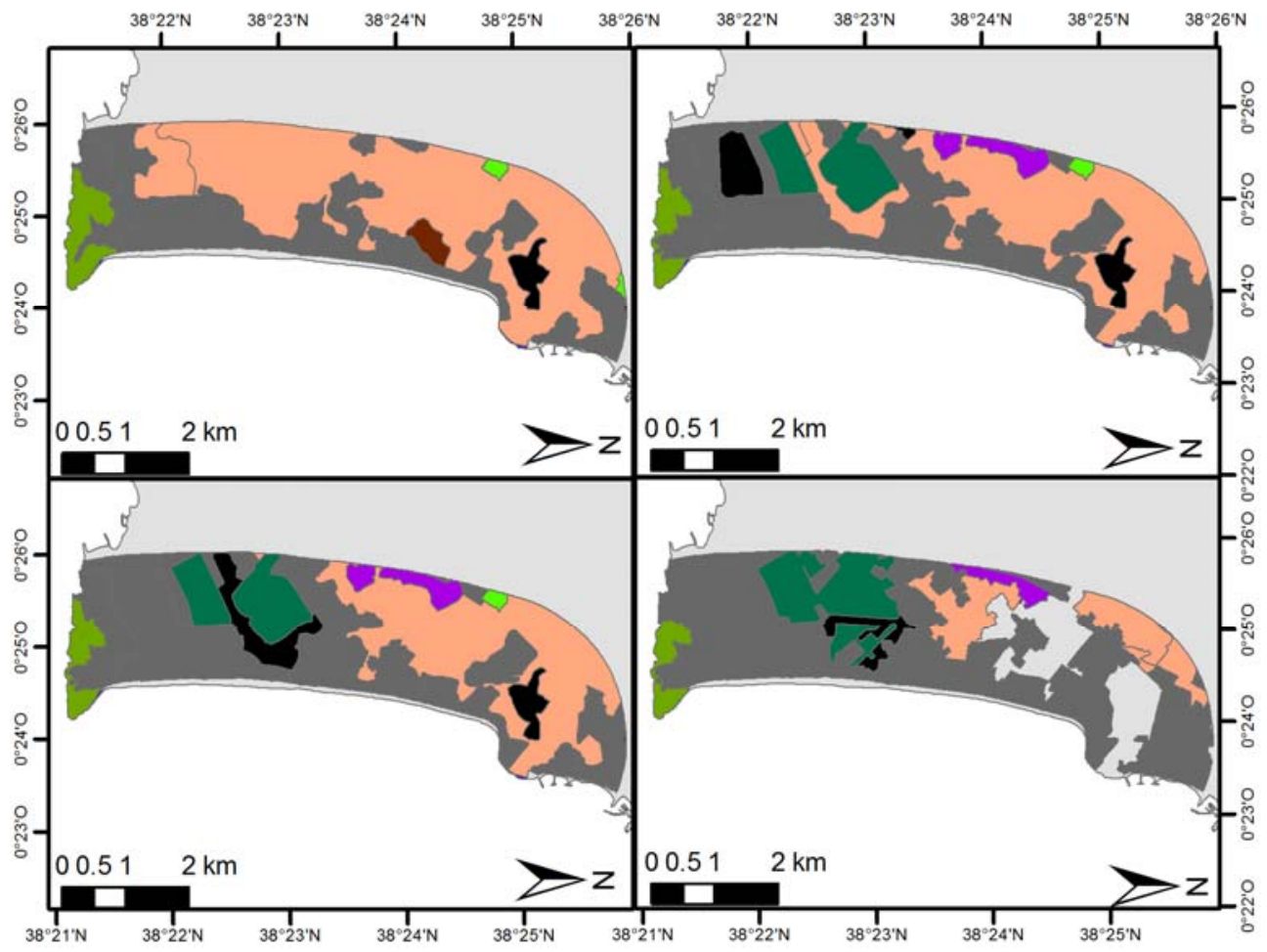

Figure 8: Land cover for San Juan beach.

over $375,000 \mathrm{~m}^{2}$, which means that $11.3 \mathrm{~m}^{3}$ were needed for every $\mathrm{m}^{2}$ of beach created. Since then, the beach has alternated periods of erosion with accretion, remaining stable at around $480,000 \mathrm{~m}^{2}$, although in recent years the erosion trend has returned.

The growth of the urbanised area is evident (Fig. 8). In 1990, 37\% of the land cover was urban fabric. In 2000 it was already $61 \%$ and in 2012 it reached $72 \%$. That is, there has been a growth of 400 ha of urbanized land. This extension of land has been won to heterogeneous agricultural areas.

\section{CONCLUSIONS}

Urban growth has been constant in the area of study, currently averaging $70 \%$ of the $2 \mathrm{~km}$ closest to the beaches. The beach whose urban fabric has grown to a greater degree is the Centro beach of Villajoyosa, although it is the one with the smallest occupied area of all, with only 53\%. However, beaches such as Poniente and San Juan have seen their urbanized area doubled since 1990. On the other hand, a general loss of sand has been detected on the beaches studied. In order to alleviate the effects of erosion and to increase the tourist attraction of the beaches, they were regenerated in the 1990s changing their typology from gravel to sand. This change has not had the desired effectiveness, with a significant loss of beach area in the first few years after nourishments. The intense urbanization of the watersheds prevents soil erosion and the contribution of sediments, increasing surface runoff, with its reflection in the erosion of the beach. It is also necessary to avoid the destruction of the dune cords that act as a reservoir of material for the beach to stop beach 
erosion. The results prove the great importance of these phenomenon. Land transformations have significantly changed the character of the territory by creating new opportunity spaces; however, these were not exempt from considerable environmental and economic costs. In the future, the alternatives must be developed in a sustainable manner with criteria of circular economy, with sufficient volumes of fills to maintain their function as tourist and coastal defence sites.

\section{REFERENCES}

[1] Scott, D., Gössling, S. \& Hall, C.M., International tourism and climate change. Wiley Interdisciplinary Reviews: Climate Change, 3(3), pp. 213-32, 2012. doi: 10.1002/ wcc. 165.

[2] Naik, D. \& Kunte, P.D., Impact of port structures on the shoreline of Karnataka, West Coast, India. International Journal of Advanced Remote Sensing and GIS, 5(5), pp. 1726-1746, 2016.

[3] Newton, A., Carruthers, T.J.B. \& Icely, J., The coastal syndromes and hotspots on the coast. Estuarine, Coastal and Shelf Science, 96, pp. 39-47, 2012. doi: http://dx.doi.org/10.1016/j.ecss.2011.07.012.

[4] Pagán, J.I., Aragonés, L., Tenza-Abril, A.J. \& Pallarés, P., The influence of anthropic actions on the evolution of an urban beach: Case study of Marineta Cassiana beach, Spain. Science of The Total Environment, 559, pp. 242-255, 2016. doi: http://dx.doi.org/10.1016/j.scitotenv.2016.03.134.

[5] Newton, A. et al., An overview of ecological status, vulnerability and future perspectives of European large shallow, semi-enclosed coastal systems, lagoons and transitional waters. Estuarine, Coastal and Shelf Science, 140, pp. 95-122, 2014. doi: http://dx.doi.org/10.1016/j.ecss.2013.05.023.

[6] Morgan, R., Preferences and priorities of recreational beach users in Wales, UK. Journal of Coastal Research, 15(3), pp. 653-667, 1999.

[7] Pagán, J.I., López, M., López, I., Tenza-Abril, A.J. \& Aragonés, L., Study of the evolution of gravel beaches nourished with sand. Science of The Total Environment, 626, pp. 87-95, 2018. doi: http://dx.doi.org/10.1016/j.scitotenv.2018.01.015.

[8] Battiau-Queney, Y., Billet, J.F., Chaverot, S. \& Lanoy-Ratel, P., Recent shoreline mobility and geomorphologic evolution of macrotidal sandy beaches in the north of France. Marine Geology, 194(1-2), pp. 31-45, 2003. doi: http://dx.doi.org/10.1016/ S0025-3227(02)00697-7.

[9] Thieler, E.R. \& William, W.D., Historical shoreline mapping (II): Application of the digital shoreline mapping and analysis systems (DSMS/DSAS) to shoreline change mapping in Puerto Rico. Journal of Coastal Research, 10(3), pp. 600-620, 1994.

[10] Heymann, Y., CORINE land cover: Technical guide: Office for Official Publ. of the Europ. Communities, 1994.

[11] Martí Ciriquián, P. \& Nolasco Cirugeda, A., Un caso paradigmático de sprawl: la costa de la provincial de Alicante. ACE: Architecture, City and Environment, 7(20), pp. 173-198, 2012. 